\title{
Research on Construction of E-Government Cloud under the Background of Internet Plus
}

\author{
Wei Wang, Bo Liu and Gang Li \\ Shandong Computer Science Center (National Supercomputer Center in Jinan), Shandong Provincial Key Laboratory of \\ Computer Networks \\ ${ }^{*}$ Corresponding author
}

\begin{abstract}
Duplication of investment, redundant construction, and the waste of resources has been the outstanding problems of construction of the domestic E-government, as the rapid development and the thorough application of the cloud computing which represent a new generation of information technology, the field of E-government construction has changed greatly. This paper puts forward two different kinds of construction modes of E-government cloud according to the Internet plus, and then compares and analyses them, and at last puts forward the suggestions for the construction of $E$ government cloud on the basis of the analysis, and the study will provide a theoretical reference for the construction of government cloud.
\end{abstract}

Keywords-internet plus; government cloud; e-government; construction; mode

\section{INTRODUCTION}

Duplication of investment, redundant construction, and the waste of resources has been the outstanding problems of construction of the domestic E-government, as the rapid development and the thorough application of the cloud computing which represent a new generation of information technology, the field of E-government construction has changed greatly. At present, we can build E-government cloud platform using cloud computing technology to provide supercomputing, storage space, software services and other applications of resources to meet the needs of E-government services. And as the Ali Cloud Computing established a long term business relation with Guizhou, and the Tencent Cloud Computing built cloud with Henan government, the Egovernment cloud has become a hotly contested hot between the cloud computing service providers.

Cloud computing platform has the feature of distributed, virtual, dynamic expansion, flexibility, and because of the particularity of the application system of government, the reliability, safety, management requirements of cloud platform is much higher than the general ones. the traditional platform. At present, government cloud is mainly divided into government public cloud and government private cloud according to the idea of cloud platform construction,. The author has carried on the research of these two kinds of construction thought, and carried out the comparison, and finally proposed some suggestions for the construction of Egovernment cloud according to the result.

\section{DEFINITION OF E-GOVERNMENT CLOUD}

Government cloud which is the organic combination of Egovernment and cloud computing technology is considered as a platform technology framework which is a kind of optimizing the government management and service functions, improving government work efficiency and service. And it is not only a kind of combined with the development of public government influence and a full range of business collaboration and sharing of information resources application, but also can give full play to the existing resources and the new generation of information technology platform. And it is literally the infrastructure which built as government application at the technical level.

Firstly cloud computing technology break the idea of fragmented fundamentally, and we can put a lot of egovernment applications and services on the cloud through overall planning, as a result, as a whole to comprehensive utilization of the equipment can be improved. Secondly, we can enhance the operation and maintenance of electronic government from introducing a third party professional services. In addition, we can also reduce a large amount of Egovernment construction investment and reduce energy consumption, to achieve the goal of energy conservation and emissions reduction. Therefore, it is useful to build a cloud platform based on cloud computing technology of the electronic government, so we can reduce the cost of construction of our country electron government, promote the resource integration and sustainable development, and we can also promote the government information sharing and business collaboration,. As a result, the level of the government information service can be improved to some extent.

\section{COMBINATION OF E-GOVERNMENT UNDER THE INTERNET PLUS}

As the internet plus initiative is put forward, the internet plus has continually infiltrate into our production life. In fact, the internet plus which is the result of the Internet ecological evolution is a new form of the development of the internet in the new period. At present, the information level has become the measure of the important symbol of comprehensive national strength and competitiveness for a country, and the use of information technology to promote E-government also has become the important condition of modernization goal of the management system and management ability for a country. The internet plus promote the government to build cloud platform 
using cloud computing, big data technology. Then the data retained in the different government departments will be collected on a network to build an uniform data pool which realize the unified management of data, and we can improve government public service ability and administrative efficiency through the generate data. Thus we can learn that it provides a good foundation for further integration of resources through the construction of e-government cloud platform, and we can take this opportunity to promote data sharing and open between departments, and promote the management, optimization, integration of the government, and finish the government affairs on the cloud through the information means, as a result, we can provide reliable IT service platform for the government departments at all levels. E-government cloud can strengthen the effective supervision of government operations, enhances the working efficiency of the government, and provide efficient, high quality of integration management and service for the social public, promote the E-government construction and application to a new height at the same time.

\section{Thoughts of Constructing E-Government Cloud}

According to the thoughts of constructing E-government cloud, the mode of building cloud can be divided into two types: E-government public cloud and E-government private cloud. The E-government public cloud can rent ali cloud, tencent cloud and other mature cloud services directly, so that the government does not need to put a lot more money into the cloud infrastructure, and they can just need to purchase cloud services which obtain supporting services. E-government private cloud can be built by professional cloud computing service companies, and the government can manage maintenance service by buying professional operations team, this approach is more flexible and can be deployed outside the Intranet or on the E-government network, also can be deployed on the Internet, and the security of the data can be controlled by the government itself.

\section{A. E-Government Public Cloud}

Public clouds usually refers to the cloud which a third party provider for the user to be able to use, and public cloud in general can be used through the Internet. Now some mature cloud services keep continuing innovation in information and communication technology, build some cloud infrastructures which are open sharing, agile and efficient, safe and reliable, and, and provide the foundation of sharing resources, opening the data support platform, the rich wisdom of e-government application, three-dimensional security and efficient operational service for government departments through close cooperation with the government industry integrators.

Under the mode of traditional data center, the government as the e-government system users and administrators have higher requirements on the stable operation and data security. While as the introduction of cloud computing, especially public clouds, the control of the business and data are transferred from the government to the cloud services. And both the intervention of third party cloud service provider role and the impact of information technology have brought more severe challenges of the cloud security.
Public cloud is a multi-tenant environment, and the safety of the public cloud does not represent the internal security between tenants. The protection of public cloud usually has multi-tenant environment compatibility, and it can't make the specific safety control of the user, especially for log analysis and audit function, the security outside the public cloud often cannot fit the actual business system, and do not have high level of customization, and thus some of its protection has lost. For the government business system whose security requirement is higher, safety protection system built on the original cloud is necessary and reasonable.

Choose the business cloud services platform which is mature and verified through large-scale and reuse existing construction experience will avoid thousands of crooked roads. With the development of technology, new technology and new service mode will be innovating, and selection of public cloud service platform will also be more options. In the future, more service providers appears with the continuous development of technology, the competition between service providers also constantly increased, and the price will be more and more transparent, then the cost would be reduced to a reasonable level unceasingly which will be more conducive to the choose the service providers for the government at all levels. Public cloud providers have large mature operations teams who can ensure the security of data storage and access and the high availability of service.

\section{B. E-Government Private Cloud}

E-government private cloud is built by using the government's internal network and information platform, and provides IT infrastructure, platform, service or application services for government with cloud computing technology. Through the E-government private cloud, we can optimize and integrate management and service functions of the government, and achieve various business processes and service functions through information means, and provide reliable IT service platform basis for the government departments at all levels.

At the same time, E-government private cloud set up cloud data center for the government to provide huge amounts of data storage, sharing, mining, search, analysis, and other services, which enables the data as intangible assets to be managed. With the integration and fusion technology of data, the data fortress between government departments is broken to realize information sharing and business collaboration between the department, which will avoid to produce information island, the redundant construction and the large construction fund. Through the analysis of the data processing, the data will be showed to the user in a more clear and intuitive way, which will be better to provide data support for the user.

Construction of government private cloud must be based on the top-level design and strategy implementation, and should give full consideration to virtualized computing, virtualization, virtualized storage, distributed cache, distributed applications, and the load balance and security policies. Through the construction of private cloud platform, we can enables realize plug and play E-government applications, resource sharing, data collection across departments, real-time monitoring and operations, etc. 


\section{Comparison of Thoughts of Constructing E-Government Cloud}

From the above two kinds of cloud, we consider the service type, scale, security and privacy from the angle of the government, and the specific comparison results as shown in “Table 1".

TABLE I. COMPARISON OF THOUGHTS OF CONSTRUCTING EGOVERNMENT CLOUD

\begin{tabular}{|l|c|c|}
\hline \multirow{2}{*}{ Item } & \multicolumn{2}{|c|}{ E-government Cloud } \\
\cline { 2 - 3 } & $\begin{array}{c}\text { E-government public } \\
\text { cloud }\end{array}$ & $\begin{array}{c}\text { E-government Private } \\
\text { Cloud }\end{array}$ \\
\hline scale & large & small \\
\hline service category & more & less \\
\hline targeted & weak & strong \\
\hline security & strong & general \\
\hline confidentiality & general & strong \\
\hline scalability & high & general \\
\hline maintainability & strong & general \\
\hline invest & low & high \\
\hline
\end{tabular}

Through comparing thoughts of construction E-government cloud, we can see that the E-government public cloud has been established by a mature cloud services whose technology is advanced and mature, and the investment is large, and the scale of the cloud is larger than the private cloud, and it can provide vary services for users with, and the security is strong, and it is easy to extend. And E-government private cloud has high confidentiality requirements, and the construction investment is larger, but it is not easy to be maintained later. Therefore, from the angle of government Angle, if the systems are not secret, the government can obtain necessary service by buying cloud service, while if the information systems demand special secret, the government needs to build private according to their own particular requirements.

\section{CONCLUSION}

In recent years, the Internet plus has risen to national strategy, and the development of cloud computing, big data industry, also be clearly written to the government work report, so governments and departments at all levels speed up the construction of the center of the cloud computing to promote cloud services combined with the electronic government affairs, which is the technology progress and the trend of times. In the construction of E-government cloud platform, the governments at all levels should choose to rent the public cloud or set up their own private cloud according to its own conditions and characteristics. Either way, the safety of the cloud platform should be given priority.

\section{ACKNOWLEDGEMENTS}

This research was partially supported by Youth Fund Project of Shandong Academy of Sciences No 2014QN012 and Project of Shandong Provincial Key Laboratory of Computer Networks on 2016.

\section{REFERENCES}

[1] Jianqiu Zhou.,Pengcheng Li,Design and Research of The Private Cloud under The PaaS Mode,Electronic Technology and Software Engineering,2015,pp.98-98.

[2] Zhongguo He,Research of The Construction of E-government Private Cloud Platform,Internet Plus Monitoring,2015,pp.116-117.

[3] Kun Yan,Construction and Implementation of Our Egovernment,Electronic Technology and Software Engineering,2014,pp.24-25.

[4] Dezhi Tong,Based on The Construction of E-government Service: Mode and Integration,Chinese Administrative Management,2008,pp.79-82.

[5] Jianxin Bi,Jianming Zheng, Research of Change of Government Function under The Perspective of E-government Cloud,E-government, 2015,pp.56-58.

[6] Bo Chen.,Huanchen Wang,E-government Construction and Government Governance Reform,Journal of China National School of Administration, 2002,pp.23-25. 